\title{
Trabalho socioeducativo no Serviço Social à luz de Gramsci: o intelectual orgânico
}

\author{
Adriana Giaqueto Jacinto \\ Universidade Estadual Paulista (UNESP)
}

Trabalho socioeducativo no Serviço Social à luz de Gramsci: o intelectual orgânico

Resumo: Este ensaio aborda a contribuição do pensamento de Gramsci para o Serviço Social tendo como referência a apreensão das relações entre política e cultura, com ênfase na dimensão educativa do trabalho do assistente social. O questionamento central é, se o(a) assistente social, enquanto profissional que trabalha com a classe expropriada de seus direitos fundamentais, pode assumir o papel de intelectual orgânico, na concepção gramsciana. Parte da história de vida e obra de Gramsci para situar o conceito de intelectual orgânico e sua relação com outros conteúdos imbricados na temática da política e cultura, refletindo sobre a ampliação do entendimento de prática pedagógica, apreendendo-a no amplo processo de lutas de classes, vinculado à questão da hegemonia.

Palavras-chave: Intelectual orgânico. Gramsci. Serviço Social. Dimensão educativa.

\section{Socio-Educational Work in Social Service in Gramscian thinking: the Organic Intellectual}

Abstract: This essay addresses the contribution of Gramscian thinking to social service using as a reference the apprehension of the relations between politics and culture, with an emphasis on the educational dimension of the work of social assistants. The central questioning is: can social assistants, as professionals who work with the class that has been expropriated of its basic rights, assume the role of organic intellectuals, in the Gramscian concept? It uses the history of the life and work of Gramsci to situate the concept of the organic intellectual and his relationship with other contents imbricated in the theme of politics and culture, reflecting on the expansion of the understanding of pedagogical practice, grasping it in the broad process of the class struggles, linked to the issue of hegemony. Keywords: Organic intellectual. Gramsci, Social Service. Educational dimension. 


\section{Introdução}

Gramsci foi educador durante toda a vida e em todos e momentos e circunstâncias, principalmente se entendemos por educação uma das mediações capazes de contribuir para a construção de uma nova consciência, uma nova sociedade, para a formação do homem novo. De sua história podemos depreender que as próprias condições de vida ensejaram o nascimento e evolução gradativa do educador militante, que compreendera, precocemente, a indissociabilidade da educação e a política, esta, em seu sentido amplo, considerando seu potencial transformador. A concepção que Gramsci tinha de educação ia além da escolar, abrangendo todos os processos que envolvessem formação de consciência. Sua história de vida revela a resistência a várias faces da desigualdade social, a que Gramsci fora submetido desde a infância pobre, que lhe usurpava o direito de acesso à educação, entretanto, contraditoriamente, as condições adversas o impulsionaram a continuar seu processo de construção do conhecimento e militância política, com o que não podiam tirar-lhe sua consciência crítica.

Gramsci nasceu em 1891, na Sardenha, uma das regiões mais pobres da Itália, experimentando as condições de vida das camadas mais baixas da população italiana ${ }^{1}$; foi vítima, antes dos dois anos, de uma doença que o deixou corcunda e prejudicou seu crescimento. Seus primeiros anos não foram diferentes das crianças pobres de Sardenha, que difere consideravelmente de Turim, na parte norte da península. Ao concluir a quinta série primária, por volta de 1903, foi obrigado a interromper seus estudos por causa das difíceis condições materiais de sua família e passou a trabalhar dez horas por dia no cartório, onde carregava pastas de processos que pesavam mais do que ele, o que ocorreu devido à prisão de seu pai, acusado de peculato e adulteração de declarações. $O$ fato de que somente quem possuía meios financeiros poderia continuar na escola gerava indignação em Gramsci. Aos 21 anos foi estudar Letras em Turim, onde trabalhou como jornalista de publicações de esquerda. Entre 1919 e 1920 vivenciou a experiência dos Conselhos de Fábrica. Em 1919, juntamente com os amigos de Universidade - Tasca, Togliatti e Terracini - Gramsci lança em Turim o jornal L'Ordine Nuovo, semanário que visava criar espaços para debater a questão do socialismo na Itália, para se tornar uma possibilidade de educação e preparação das massas para a práxis revolucionária. Conheceu a mulher, Julia Schucht, em Moscou, para onde foi enviado como representante da Internacional Comunista. Deputado eleito pelo Partido Comunista, a imunidade parlamentar, que legalmente o protegia, não foi suficiente para salvá-lo da condenação a vinte anos de reclusão. Foi preso em 1926 pelo regime fascista de Benito Mussolini, cumprindo dez anos, pois morreu em 1937, com 46 anos. Ficou célebre a frase dita pelo juiz que o condenou: "Temos que impedir esse cérebro de funcionar durante vinte anos".

Apesar de todas as condições contrárias, Gramsci foi um educador; construiu um legado a outros educadores, dentro do significado que atribuía à educação. No cárcere, lutou pelo direito de ler e escrever e assim que o conseguiu, tentando romper o isolamento com o mundo exterior, passou a escrever cartas à família e aos companheiros do partido e empreendeu planos de estudo, cujo desenvolvimento concreti-

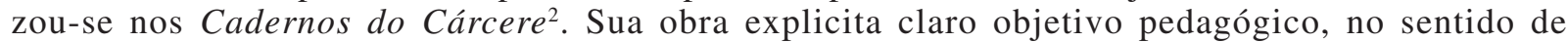
instrumentalizar a classe operária para que ela assuma a consciência da própria história e seja protagonista da sua emancipação. Gramsci evidencia a importância do papel do intelectual na luta de classes, no desenvolvimento da ação revolucionária.

A questão é: como profissional que atua junto com a classe expropriada de seus direitos fundamentais, o(a) assistente social pode assumir o papel de intelectual orgânico, na concepção gramsciana? A origem do Serviço Social, como profissão inserida na divisão sociotécnica do trabalho, está profundamente relacionada com o agravamento da questão social em um determinado contexto histórico marcado pelo capitalismo monopolista, que acirra as contradições provenientes da relação capital e trabalho.

No exercício das dimensões ético-política, técnico-operativa e teórico-metodológica, o(a) assistente social desenvolve um trabalho eminentemente educativo. Esta dimensão tem estreito vínculo com a organização da cultura visto que as relações profissionais que se estabelecem na atuação profissional dos(as) assistentes sociais concretizam-se não somente sob a forma de ação material, mas fundamentalmente ideológica, nos espaços cotidianos de vida e de trabalho de segmentos das classes expropriadas de seus direitos, interferindo na reprodução física e subjetiva desses segmentos. O grande desafio que se coloca na conjuntura atual é, através da organização popular, estimular o potencial transformador destas classes. No enfrentamento deste desafio, o(a) assistente social pode ser caracterizado como educador(a)? As ideias de Gramsci podem contribuir, na contemporaneidade, com o Serviço Social? Este ensaio apresenta reflexões a respeito da contribuição de Gramsci para o trabalho do(a) assistente social, a partir do conceito de intelectual orgânico. 


\section{O intelectual orgânico para Gramsci}

A questão dos intelectuais está presente no conjunto das reflexões de Gramsci, tanto pré-cárcere como em todos os planos que elaborou para os escritos carcerários. É uma categoria a ser compreendida no contexto da construção de uma nova mentalidade, nova educação, nova cultura, um novo homem. Para Gramsci, a hegemonia constitui-se como categoria fundante no processo de transformação social. Fundamentado em Marx, Engels e Lenin, compreende que o Estado nasce das classes, é expressão da luta de classes e do domínio de uma delas. Na sociedade civil realizam-se as condições materiais e ideológicas de vida, é o lugar onde se vivem as relações de produção e também de cultura, lugar da construção de uma hegemonia. A classe dominante obtém o consenso em torno de seus objetivos e desta forma, exerce a direção política. Por outro lado, contraditoriamente, sociedade civil é também o lugar da construção de uma contra-hegemonia.

A hegemonia pode ser preparada por uma classe que lidera a constituição de um bloco histórico, amplo e para durável aliança de classes e frações. Gramsci (COUTINHO, 2007) supera o conceito de Estado como sociedade política ou aparelho coercitivo que visa adequar as massas às relações de produção. Ele distingue duas esferas no interior das superestruturas. Uma delas é representada pela sociedade política - Estado em sentido estrito ou Estado-coerção -, conjunto de mecanismos através dos quais a classe dominante detém o monopólio legal da repressão e da violência, e que se identifica com os aparelhos de coerção dos grupos burocráticos ligados às forças armadas e policiais e à aplicação das leis. A outra é a sociedade civil, ou hegemonia de um grupo social sobre a sociedade, exercida através de um conjunto das instituições responsáveis pela elaboração e/ou difusão de valores simbólicos e de ideologias, compreendendo o sistema escolar, os partidos políticos, as corporações profissionais, os sindicatos, a organização material da cultura (revistas, jornais, editoras, os meios de comunicação de massa), as instituições de caráter científico e cultural etc. Sociedade civil e sociedade política diferenciam-se pelas funções que exercem na organização da vida cotidiana e, mais especificamente, na articulação e na reprodução das relações de poder. Em conjunto, formam o Estado em sentido amplo: "sociedade política + sociedade civil, isto é, hegemonia revestida de coerção" (GRAMSCI apud COUTINHO, 2007, p. 127). Coutinho (2007), ainda, destaca os conceitos de guerra de posição e guerra de movimento, propostos por Gramsci, contextualizando suas construções teóricas. Afirma que a teoria ampliada do Estado é a base que permitiu a Gramsci responder à questão do fracasso da revolução nos países ocidentais, porque não se levou em conta a diferença estrutural existente entre as formações sociais do oriente, caracterizadas pela debilidade da sociedade civil em contraste com o predomínio quase absoluto do Estado-coerção e as formações sociais do ocidente, onde se dá uma relação mais equilibrada entre sociedade civil e sociedade política. Nas formações orientais, a predominância do Estado-coerção impõe à luta de classes uma estratégia de ataque frontal, uma guerra de movimento; no ocidente as batalhas devem ser travadas incialmente no âmbito da sociedade civil, visando à conquista de posições e de espaços, a guerra de posição:

O critério central para a resolução da crise é a iniciativa dos sujeitos políticos coletivos, a capacidade de fazer política, de envolver grandes massas na solução de seus próprios problemas, de lutar cotidianamente pela conquista de espaços e posições, sem perder de vista o objetivo final, ou seja, o de promover transformações de estrutura que ponham fim à formação econômico-social capitalista. Se a crise econômica não se traduz espontaneamente na desagregação do bloco dominante (mas pode até, em certas condições, favorecer uma reagregação desse bloco), isto significa que tal desagregação depende diretamente da capacidade da classe dominada de fazer política; em outras palavras, de conquistar progressivamente para si a hegemonia perdida, ou em vias de perder-se, pela classe dominante (COUTINHO, 2007, p. 155, grifos do autor).

A análise gramsciana amplia, assim, o conceito de prática pedagógica, apreendendo-a no amplo processo de lutas de classes, vinculado à questão da hegemonia. Para Gramsci $(1978$, p. 46), toda relação de hegemonia é necessariamente pedagógica, não limita essa pedagogia às relações especificamente escolásticas, mas situaas "em toda sociedade no seu conjunto e para cada indivíduo em relação aos outros indivíduos, entre grupos intelectuais e não intelectuais, entre governantes e governados, entre elites e sequazes, entre dirigente e dirigidos, entre vanguardas e corpos de exércitos". A revolução, como mudança total e profunda dos sistemas sociais, começa a ser realizada todos os dias, em todos os lugares, é um processo que pode ter início em âmbito educacional, cotidiano e molecular. Nesse sentido, Gramsci pretende a criação de um novo bloco histórico, a partir de uma nova concepção de mundo, que seja capaz de ascender do nível do senso comum a uma consciência filosófica, de uma real compreensão do mundo dividido em classes.

O liberalismo penetrou nas consciências e se fez senso comum. A construção de uma contra-hegemonia burguesa é tarefa a ser feita pela classe trabalhadora na busca de outra filosofia. É preciso fazer o caminho no âmbito do pensamento revolucionário do operariado, desmontando a hegemonia burguesa, criando outra con- 
cepção de mundo, capaz de fazer o homem liberto: “Pode se empregar a expressão 'catarses' para indicar a passagem do momento puramente econômico (ou egoísta-passional) ao momento ético-político, isto é, a elaboração superior da estrutura em superestrutura na consciência dos homens. Isto significa, também, a passagem do ‘objetivo ao subjetivo' e da 'necessidade à liberdade”" (SABÓIA, 1990, p. 49).

Para Gramsci (2000b, v. 2, p. 18) "todos os homens são intelectuais, mas nem todos os homens têm na sociedade a função de intelectuais". O critério de distinção não estaria no que é intrínseco às atividades intelectuais, mas no conjunto do sistema de relações no qual estas atividades e, portanto, os grupos que as personificam se encontram no conjunto geral das relações sociais: "Formam-se assim, historicamente, categorias especializadas para o exercício da função intelectual; formam-se em conexão com todos os grupos sociais, mas, sobretudo, em conexão com os grupos sociais mais importantes, e sofrem elaborações mais amplas e complexas em ligação com o grupo social dominante" (GRAMSCI, 2000b, v. 2, p. 18). Gramsci (2000b) formula, ainda, a distinção entre intelectuais orgânicos e intelectuais tradicionais, ou seja, como categoria orgânica de cada classe fundamental e como categoria tradicional, isto é, como categoria nascida, sim, historicamente em função de uma determinada classe, mas cristalizando-se, depois, por sua ininterrupta continuidade histórica, como casta. A mais típica dessas últimas categorias de intelectuais é o clero, monopolizador durante uma fase histórica inteira de várias funções sociais, entre elas precisamente a escola e a instrução em geral.

A organicidade dos intelectuais define-se pela consciência e pela prática com uma determinada classe, define-se a partir da função e do vínculo que os mesmos mantêm com a classe que representam. Os intelectuais orgânicos atuam nos processos de formação de uma consciência crítica, ou seja, estabelecem uma relação orgânica com a classe que se identificam. É do contato e das observações das visões de mundo, das experiências, das ações e comportamentos das classes subalternas que os intelectuais devem se alimentar para suas formulações teóricas e ações políticas. É firmada uma aliança entre o intelectual orgânico e a classe que representa, existe uma identidade de objetivos. Se ele se identifica e se sensibiliza com o projeto da classe dominada, apoia, reflete em conjunto, orienta, informa, estimula, facilita espaços, convive e vive as esperanças e iniciativas dos que buscam a superação da dominação em quaisquer formas que se apresente: "O modo de ser do novo intelectual não pode mais consistir na eloquência, motor exterior e momentâneo dos afetos e das paixões, mas numa inserção ativa na vida prática, como construtor, organizador, persuasor permanente" (GRAMSCI, 2000b, v. 2, p. 53).

Simionatto (2009) esclarece que a categoria subalterno e o conceito de subalternidade têm sido utilizados, contemporaneamente, na análise de fenômenos sociopolíticos e culturais, normalmente para descrever as condições de vida de grupos e camadas de classe em situações de exploração ou destituídos dos meios suficientes para uma vida digna. Contudo, no pensamento gramsciano, tratar das classes subalternas exige mais do que isso, trata-se de recuperar os processos de dominação presentes na sociedade, a superação da condição de subalternidade requer a elaboração de uma concepção de mundo crítica e coerente, necessária para suplantar o senso comum e tornar as classes subalternas capazes de produzir uma contra-hegemonia. A preocupação de Gramsci com a passagem das classes subalternas à posição hegemônica está vinculada à necessidade do desenvolvimento de um novo projeto cultural que seja capaz de propiciar a elaboração de uma concepção de mundo, própria das classes subalternas, libertando-a da racionalidade capitalista (CARDOSO, 1995).

Gramsci, no contexto histórico em que estava situado, encaminha a perspectiva de autonomização das classes subalternas através da proposta dos conselhos de fábrica e, posteriormente, do partido comunista, entendendo que o partido político desempenha função fundamental para que a classe proletária possa enfrentar a hegemonia burguesa. Nesta linha de raciocínio, não seriam os intelectuais, individualmente, que possibilitariam às classes dominadas alcançarem a hegemonia, mas o partido político, enquanto intelectual coletivo, organizador de uma reforma intelectual e moral. Dessa forma, marca a importância da atuação do intelectual junto com a classe na elaboração de uma nova concepção de mundo, no desvelamento das relações antagônicas e das contradições que perpassam a sociedade, bem como das possibilidades para sua superação (SIMIONATTO, 1995).

O intelectual em Gramsci é, portanto, aquele que tem por função realizar o movimento entre concepção de mundo e contexto histórico-social, procurando estimular formas organizativas que permitam que a ação revolucionária se desenvolva.

\section{O(A) Assistente social pode configurar-se como intelectual orgânico?}

A sociedade do capital tem gerado a desigualdade em um nível que a barbárie chega ser banalizada. Vivemos num mundo onde a ampliação das riquezas contrasta fortemente com o aprofundamento da miséria. Vivemos na era da financeirização e mundialização do capital, em que a maioria da população carece de 
emprego, acesso à alimentação, saúde, educação, moradia. O capitalismo, construção histórica da exploração, é que aliena o trabalho de sua condição humana. Desta forma, não pertence à natureza do trabalhador, mas é condição para que esse sobreviva minimamente; vai gerar riquezas, mas pouco vai poder usufruir delas, pois o salário que recebe pela venda de sua força de trabalho é enormemente menor do que os bens que ele produziu. $\mathrm{O}$ trabalho alienado, estranhado, em nenhum momento da história levou tanto à desumanização do próprio homem, uma vez que não seria preciso a exploração para se produzir riqueza. $\mathrm{O}$ fruto da produção não pertence ao trabalhador e o que recebe em troca não é suficiente para sua sobrevivência. $O$ capitalismo não gera apenas a desigualdade, mas todo o aparato cultural e ideológico para aceitação da mesma como sendo natural. Com as mudanças estruturais ocorridas na organização do trabalho - a passagem do fordismo à acumulação flexível - temos a mudança no modo de produção da vida social, em que o tempo de vida disponível das pessoas está também atravessado pela lógica do trabalho estranhado. Toda a vida do trabalhador pertence, assim, ao capital.

A origem do Serviço Social, como profissão inserida na divisão sociotécnica do trabalho, está relacionada com a questão social, em um determinado contexto histórico, marcado pelo capitalismo monopolista. Dispondo de uma dimensão estrutural - enraizada na produção social contraposta à apropriação privada dos frutos do trabalho -, a questão social atinge visceralmente a vida dos sujeitos que se veem obrigados a lutar pelos direitos sociais.

O Serviço Social é a profissão requisitada para lidar com as expressões da questão social, entretanto, é importante destacar que esta, por sua vez, não teria existido se não fossem as revoltas e mobilizações dos trabalhadores por condições dignas de sobrevivência. Nesse sentido, enquanto profissão, o Serviço Social nasce já no dilema de servir ao poder dominante, visto que, na divisão sociotécnica do trabalho, é a profissão que deve ter a capacidade de responder às demandas advindas da questão social, todavia, para amenizar conflitos, gerenciar a pobreza, criar estratégias de solução de problemas sociais a partir da própria classe que mais sofre com os mesmos. Além disso, o assistente social é o profissional que atua através de políticas sociais precárias, com parcos recursos e por outro lado, tem em sua profissão um projeto ético-político que vislumbra, enquanto horizonte, outra sociedade, livre da exploração do trabalho e consequentemente, permeada por relações sociais verdadeiramente humanas.

$\mathrm{O}(\mathrm{A})$ assistente social, tendo diante de si este horizonte, também é um(a) trabalhador(a), vivenciando a mesma necessidade de sobrevivência, tendo também que lutar pelos próprios direitos, vivendo também as condições do trabalho assalariado, estranhado, alienado, atuando através de políticas sociais precarizadas, focalizadas, minimizadas. Como esperar desse(a) profissional que seja o(a) organizador(a) das massas, persuasor(a) permanente, especialista a serviço das classes dominadas? Pode-se dizer, portanto, que o primeiro desafio é a própria conjuntura que vivenciamos, pois o projeto ético-político do Serviço Social vai contra a corrente do ideário neoliberal que rege a sociedade atual.

Ao viabilizar o acesso a um recurso material concreto ou contribuir com o acesso a um direito do usuário, o(a) assistente social não apenas repassa o material, mas o faz dentro de um processo educativo, que exige diálogo competente, troca de informações, orientações, potencialização da organização e mobilização dos sujeitos para a conquista dos seus direitos. A dimensão socioeducativa é, portanto, fundante na identidade do Serviço Social. O trabalho do(a) assistente social situa-se predominantemente no campo político-ideológico.

A atuação do(a) assistente social tanto pode favorecer a interação entre os sujeitos sociais, estimulando a reflexão sobre a ideologia dominante, contribuindo com a mobilização social, com a instrumentalização da população atendida para a busca de seus direitos, quanto pode vincular aos interesses dominantes, servindo como poderoso instrumento de legitimação da desigualdade social e de aprofundamento das relações de subalternização.

Se na sociedade capitalista dominam valores e ações destrutivos dos homens, também estão presentes forças anticapitalistas e valores emancipatórios. Essa mesma sociedade apresenta um terreno minado de resistências e lutas travadas no dia-a-dia de uma conjuntura adversa para os trabalhadores, as quais carecem de maior organização para terem força na arena pública. Pensando no trabalho desenvolvido pelo(a) assistente social, temos que cada vez mais é requisitado a atuar junto aos segmentos mais empobrecidos da classe trabalhadora, para contribuir na necessária redução das desigualdades socioeconômicas, por meio de viabilização de serviços, benefícios, programas sociais, laudos, pareceres, avaliações sociais, a 
partir de estratégias, ações e instrumentos. É a partir da legitimidade profissional que o(a) assistente social, através da mesma ação de responder às requisições institucionais, pode favorecer os interesses da classe trabalhadora. Trata-se de reafirmar a condição de classe, que se expressa também na pobreza imposta à classe trabalhadora, com a destituição do direito de usufruir da riqueza social-mente produzida. O trabalho do(a) assistente social pode caminhar no sentido de contribuir com a consciência de classe dos trabalhadores atendidos, buscando caminhos para enfrentamento das expressões da questão social, de forma coletiva, entendendo-se o caráter coletivo, não no sentido da quantidade, mas da qualidade do potencial de aprendizagem que as lutas sociais por efetivação dos direitos contêm.

Luiz (2013), fundamentada em Gramsci, chama a atenção para a possibilidade de rupturas moleculares, ressaltando que a posição hegemônica é uma construção histórica e, por isso, suscetível de contra-hegemonia. As rupturas moleculares - socialização do poder e da política, a ocupação de posições, a elevação cultural e do conhecimento, a consciência crítica - poderão contribuir para uma nova visão de mundo, desarticulando a ideologia dominante. A libertação do estágio inicial para um novo estágio de contra-hegemonia é necessariamente uma relação pedagógica, na medida em que indivíduos, grupos ou segmentos em relação com outros pares absorvem as experiências e amadurecem concepções e práticas autônomas, podendo multiplicar possibilidades de emancipação coletivas.

Pode-se dizer que o processo participativo é por si só educativo (GOHN, 1999), visto que se aprende a eleger, estabelecer rodízio de poder, tensionar os mandantes a servirem a comunidade, a decodificar o porquê das restrições e proibições, a não ter medo de tudo que foi inculcado como inacessível e acreditar no poder da fala e das ideias quando expressas em lugares e ocasiões adequadas. Vasconcelos (2000, p. 146) acrescenta: "No que se refere à concretização dos interesses das classes subalternas, o processo de mobilização desenvolvido pelos assistentes sociais visa à organização dessas classes onde é possível gerar e socializar conhecimentos, constituindo sujeitos coletivos capazes de participar da construção da hegemonia das referidas classes".

$\mathrm{O}(\mathrm{A})$ assistente social, ao trabalhar com grupos e classes sociais, coloca-se como facilitador(a) das transformações sociais. A dimensão de sua prática é o coletivo, a classe social, especialmente as classes populares, com as quais deve construir alianças significativas. A função educativa dos(a) assistentes sociais, contida em seu projeto ético-político profissional, segundo Cardoso e Maciel (2000, p. 144):

concretiza-se fundamentalmente através do estabelecimento de novas relações pedagógicas entre o assistente social e os usuários de seus serviços. Relações estas favorecedoras de um processo de participação dos sujeitos envolvidos, numa dupla dimensão: de conhecimento crítico sobre a realidade e recursos institucionais tendo em vista a construção de estratégias coletivas em atendimento às necessidades e interesses das classes subalternas; e de mobilização desses sujeitos, instrumentalização de suas lutas e manifestações coletivas na perspectiva do fortalecimento e avanço da organização das referidas classes como classe hegemônica.

Sob essa perspectiva, são necessárias ações que venham fortalecer a luta e a resistência da classe trabalhadora e, portanto, as atividades socioeducativas devem levar as camadas populares a desenvolverem coletivamente suas próprias formas de posicionamento diante das relações da vida social e de analisá-las e explicá-las. Isso passa por um processo de conscientização. Trata-se de estabelecer uma aliança comprometida em apoiar as lutas e reivindicações das camadas populares, tentando contribuir para sua mobilização, para a ampliação de sua participação e de seu fortalecimento enquanto grupo organizado.

Abreu $(2004 ; 2011)$ afirma que as relações pedagógicas no trabalho do assistente social concretizamse sob a forma de ação material e ideológica, nos espaços cotidianos de vida e de trabalho de segmentos das classes subalternas. A mesma ressalta, ainda, que a função pedagógica desempenhada pelos assistentes sociais na sociedade brasileira ao longo da sua trajetória histórica, considerando os distintos e contraditórios projetos culturais, define-se a partir de estratégias educativas postas na luta de classes, em que podemos distinguir duas direções: a) as estratégias educativas subalternizantes, vinculadas à necessidade de reprodução das relações de dominação e exploração do capital sobre o trabalho e o conjunto da sociedade; b) as estratégias educativas emancipatórias, vinculadas à necessidade histórica de construção de uma alternativa societária à ordem do capital.

Dessa forma, a mobilização social e a organização, como elementos constitutivos e condições indispensáveis na concretização das práticas educativas desenvolvidas pelo assistente social, vinculam-se a diferentes projetos profissionais e societários. Projetos de interesse das classes subalternas ou projetos de interesses das classes dominantes, cujas perspectivas são respectivamente: de superação da sociedade capitalista, tendo como horizonte a conquista da emancipação humana ${ }^{3}$, passando pelas lutas democráticas 
e pelo fortalecimento de processos emancipatórios das classes subalternas e de toda a sociedade; ou de manutenção da ordem capitalista, tendo como exigência a subalternidade da classe trabalhadora, enquanto segmento das classes subalternas.

Não há como negar o caráter contraditório da intervenção do(a) assistente social, uma vez que seu projeto ético político aponta para a direção social que tem como horizonte a emancipação humana, e sua atuação se dá dentro da sociedade capitalista, através de espaços que se configuram estratégicos para manutenção desta sociedade. O projeto profissional é parte de um projeto de sociedade que, na atualidade, está num momento predominantemente conservador, contrarrevolucionário, fragmentador das lutas sociais, o que vem dificultando a construção de um movimento de massas.

Diante da hegemonia do capital, o(a) assistente social, enquanto intelectual orgânico, ao inserir-se neste campo contraditório, precisa buscar alternativas que possam favorecer o exercício de formas emancipatórias de consciência social, contribuindo com a qualificação da participação política, da mobilização, da organização política das classes subalternas. Não há um receituário a seguir, no entanto, Gramsci (2000a, v. 1, p. 221-222) assinala as condições para a configuração do intelectual orgânico, afirmando ser necessária a:

\begin{abstract}
Passagem do saber ao compreender, ao sentir, e, vice-versa, do sentir ao compreender, ao saber. O elemento popular 'sente', mas nem sempre compreende ou sabe; o elemento intelectual 'sabe', mas nem sempre compreende e, menos ainda, 'sente'. [...] O erro do intelectual consiste em acreditar que se possa saber sem compreender e, principalmente, sem sentir e estar apaixonado. [...] [O intelectual] deve sentir as paixões elementares do povo, compreendendo-as e, portanto, explicando-as e justificando-as em determinada situação histórica, bem como relacionando-as dialeticamente com as leis da história, com uma concepção do mundo superior, científica e coerentemente elaborada, com o 'saber'; não se faz política-história sem essa paixão, isto é, sem esta conexão sentimental entre intelectuais e povo-nação. Na ausência deste nexo, as relações do intelectual com o povo-nação são, ou se reduzem, a relações de natureza puramente burocrática e formal; os intelectuais se tornam uma casta ou um sacerdócio.
\end{abstract}

\title{
Considerações finais
}

No pensamento gramsciano a hegemonia tem uma função pedagógica, enquanto processo de constituição ideológica das classes subalternas, que se realiza tanto para afirmar a direção dessas classes quanto para superar a sua condição de subalternidade, construindo uma nova ordem social. A política, no sentido amplo, não se restringe ao Estado e nem à relação entre governados e governantes. Ela é tratada por Gramsci como o momento que permite aos homens ultrapassarem os determinismos econômicos, transformando-os em meio de sua liberdade, o que redunda em investimentos voltados para criar nova forma ético-política de vida em sociedade, dando origem à constituição de um sujeito histórico, graças à elaboração de uma vontade coletiva. Por isso, os projetos profissionais são indissociáveis de projetos societários, o que supõe impregnar o exercício profissional da grande política.

Da mesma forma, a questão do intelectual é tratada por Gramsci no interior do conjunto das relações sociais da sociedade de classes. A função do intelectual define-se pela conservação ou construção de projetos hegemônicos de classe. Para os intelectuais orgânicos vinculados a um projeto societário emancipador das classes subalternas, a função da construção de uma contra-hegemonia está na ação desenvolvida nos processos de formação de uma consciência crítica que supere o senso comum. Os intelectuais estabelecem uma relação orgânica com a classe que se identifica; é firmada uma aliança entre o intelectual orgânico e a classe que representa; existe uma identidade de objetivos.

$\mathrm{O}(\mathrm{A})$ assistente social pode identificar-se com o projeto da classe dominada, apoiando, refletindo, orientando, informando, estimulando a organização coletiva. Toda e qualquer ação profissional do(a) assistente social está referenciada ao projeto ético político do Serviço Social, podendo aproximar-se ou distanciar-se dele, entendendo-se este projeto não como um ponto de chegada, mas como uma processualidade, dentro de uma sociabilidade estruturada na busca da emancipação humana, possível não apenas pelo acesso aos direitos de cidadania, mas pela formação do homem integral, formação que exige a transformação radical desta sociedade, que é baseada na exploração do homem pelo homem.

Qualquer que seja o espaço de atuação do(a) assistente social, ele(a) é um(a) profissional que tem um papel essencial visto que exerce uma função eminentemente educativa e organizativa, atuando com as classes trabalhadoras. Uma das exigências colocadas pelo conjunto das atuais transformações sociais à dimensão socioeducativa do Serviço Social, sob a ótica de manutenção do poder dominante, visa conformar o modo de vida da população à nova racionalização do processo de produção e do trabalho. Todavia, dado ao movimento contraditório da sociedade, no 
contexto adverso à implementação do projeto ético-político do Serviço Social, podem ser construídos os elementos de crítica e resistência à ordem estabelecida, sob o ponto de vista das classes subalternas.

$\mathrm{O}(\mathrm{A})$ assistente social, no desenvolvimento de seu trabalho cotidiano, pode contribuir com o estímulo à consciência crítica, com o desvelamento da realidade social, com a instrumentalização para a organização popular e o protagonismo dos sujeitos sociais. Neste sentido, o(a) assistente social pode configurar-se como intelectual orgânico às classes subalternas com as quais atua, apreendendo junto com as mesmas, estratégias para a conquista da contra-hegemonia, um processo que se faz e refaz em cada ação, em cada reflexão, em cada nova descoberta. É um processo educativo por excelência, uma vez que o conhecimento é construído no coletivo, através de uma nova leitura da realidade, de processos de reflexão, de engajamento político, no sentido da "grande política", aquela em que se constroem coletivamente caminhos para outra sociedade verdadeiramente humana e possível.

\section{Referências}

ABREU, M. M. Serviço Social e a organização da cultura: perfis pedagógicos da prática profissional. São Paulo: Cortez, 2011. . A dimensão pedagógica do Serviço Social: bases histórico-conceituais e expressões particulares na sociedade brasileira. Serviço Social \& Sociedade, São Paulo: Cortez, ano 25, n. 79, p. 43-71, set. 2004.

CARDOSO, F. G. Organização das classes subalternas: um desafio para o Serviço Social. São Paulo: Cortez, 1995.

; MACIEL, M. Mobilização social e práticas educativas. In: Capacitação em Serviço Social e política social: o trabalho do assistente social e as políticas sociais. mod. 4. Brasília, DF: Ed. UnB, 2000. p. 141-149.

COUTINHO, C. N. Gramsci: um estudo sobre seu pensamento político. Rio de Janeiro: Civilização Brasileira, 2007.

GOHN, M. da G. Movimentos sociais e educação. São Paulo: Cortez, 1999.

GRAMSCI, A. Cadernos do cárcere: introdução ao estudo da filosofia. A filosofia de Benedetto Croce. Edição e tradução Carlos Nelson Coutinho; coedição, Luiz Sérgio Henriques e Marco Aurélio Nogueira. Rio de Janeiro: Civilização Brasileira, 2000a. v. 1.

Cadernos do cárcere: os intelectuais. O princípio educativo. Jornalismo. Edição e tradução Carlos Nelson Coutinho;

coedição, Luiz Sérgio Henriques e Marco Aurélio Nogueira. Rio de Janeiro: Civilização Brasileira, 2000b. v. 2.

Obras escolhidas. Tradução Manuel Cruz. São Paulo: Martins, 1978.

LUIZ, D. E. C. Emancipação e Serviço Social. Ponta Grossa: Ed. UEPG, 2013.

MAESTRI, M.; CANDREVA, L. Antonio Gramsci: vida e obra de um comunista revolucionário. São Paulo: Expressão Popular, 2001.

MARX, K. Para a questão judaica. Tradução José Barata-Moura. São Paulo: Expressão Popular, 2009.

Glosas críticas marginais ao artigo "O Rei da Prússia e a Reforma Social", de um prussiano. [Tradução Ivo Tonet]. São

Paulo: Expressão Popular, 2010.

SABÓIA, B. A filosofia Gramsciana e a educação. Em Aberto, Brasília, DF: Inep, ano 9, n. 45, p. 47-56, jan./mar. 1990.

SIMIONATTO, I. Gramsci: sua teoria, incidência no Brasil, influência no Serviço Social. São Paulo: Cortez, 1995.

Classes subalternas, lutas de classe e hegemonia: uma abordagem gramsciana. Revista Katálysis, Florianópolis: Edufsc, v. 12, n.

1, p. 41-49, jan./jun. 2009.

VASCONCELOS, A. M. O trabalho do assistente social e o projeto hegemônico no debate profissional. In: CAPACITAÇÃO em Serviço Social e política social: o trabalho do assistente social e as políticas sociais. mod. 4. Brasília, DF: Ed. UnB, 2000. p. $127-137$.

\section{Notas}

1 Os dados biográficos podem ser encontrados nos estudos de Coutinho (2007), Simionatto (1995), Maestri e Candreva (2001), entre outros.

2 Gramsci utilizou 33 cadernos escolares, que lhe iam sendo fornecidos à medida que os requisitava ao diretor do presídio. Quatro desses cadernos são inteiramente dedicados a exercícios de tradução. Palmiro Togliatti publicou os Cadernos do cárcere entre 1948 e 1951. Ele reagrupou as notas de Gramsci por grandes temas. Foram seis livros: Maquiavel, o Estado e a política moderna; Literatura e vida nacional; Passado e presente; $O$ materialismo histórico e a filosofia de Benedetto Croce; $O$ Risorgimento; Os intelectuais e a organização da cultura. Em 1975, Valentino Gerratana publicou os textos como eles aparecem nos cadernos originais. Na edição crítica (1975), conhecida como edição Gerratana, (Quaderni del cárcere, Turim, Eunaldi, 1975, 4 v.), os cadernos se dividem, segundo indicações do próprio Gramsci, em cadernos especiais e cadernos miscelâneos. Nos primeiros, Gramsci agrupou notas sobre temas específicos; nos segundos, reuniu apontamentos sobre diferentes assuntos. Nesta edição, Gerratana distingue as notas em textos A, B e C. Os textos A são aqueles que Gramsci cancela e depois retoma, com maiores ou menores alterações, em textos C; os textos B são os de redação única (GRAMSCI, 2000b).

3 Emancipação humana está sendo entendida na concepção de Marx (2009, 2010), que faz uma distinção entre emancipação política e emancipação humana A primeira seria uma emancipação da classe burguesa, isto é, parcial, da exploração do homem 
pelo homem, da sociedade de classes. Remete, portanto, ao conjunto de direitos políticos e sociais que garantem uma liberdade e igualdade formais dos cidadãos; realiza-se no interior da ordem capitalista, portanto, na manutenção de um sistema estruturalmente desigual. A emancipação humana, por sua vez, só será alcançada com a eliminação da propriedade privada dos meios essenciais de produção, da exploração do trabalho e da concentração de riqueza socialmente produzida. orre na necessária superação da ordem do capital para o comunismo.

\section{Adriana Giaqueto Jacinto}

drigiaqueto@gmail.com

Doutora em Serviço Social pela Universidade Estadual Paulista (Unesp/Franca).

Professora nos cursos de Graduação e Pós-graduação em Serviço Social na Faculdade de Ciências Humanas e Sociais (FCHS) da Universidade Estadual Paulista (Unesp/Franca).

\section{Unesp/Franca}

Av. Eufrásia Monteiro Petráglia, 900 - Jardim Antônio Petráglia

Franca - São Paulo- Brasil

CEP: 14409-160 